\title{
Prognostic significance of blood pressure in frail older adults
}

\author{
Yasuharu Tabara ${ }^{1,2}$
}

Received: 6 October 2021 / Revised: 18 November 2021 / Accepted: 18 November 2021 / Published online: 16 December 2021

(c) The Japanese Society of Hypertension 2021

Hypertension is a well-established risk factor for cardiovascular diseases and mortality. However, the clinical significance of hypertension may not be common to all individuals; high blood pressure (BP) in older persons did not always show a significant association with worse outcomes. For example, in a longitudinal study based on $\geq 12,000$ community-dwelling older adults, men aged 65-84 years with systolic $\mathrm{BP}<130 \mathrm{mmHg}$ have significantly lower mortality, while in the older subpopulation $(\geq 85$ years), the lowest mortality was observed in a subgroup with systolic $\mathrm{BP} \geq 180 \mathrm{mmHg}$ [1]. Similar results were observed in another longitudinal study of 85 -year-old adults [2] and older nursing home residents (mean age: 85 years) [3].

A higher mortality rate in the normal BP range was also noted in observational studies of older patients with treated hypertension. The Berlin Initiative Study that included $\geq 70$ year-old patients taking antihypertensive drugs found that, compared with non-normalized BP, normalized BP was associated with an increased risk of all-cause mortality in patients $\geq 80$ years old, but not in aged 70-79 years old patients [4]. Studies on nursing home residents older than 80 years old reported that individuals with low systolic blood pressure $(<130 \mathrm{mmHg})$ with multiple BP medications had the highest mortality rate [5]. Although a database analysis study using the English National Health Service observed a U-shaped association between treated BP levels and all-cause mortality in older ( $\geq 80$ years old) patients with hypertension, the higher mortality in the high systolic BP range might be due to the high incidence rate of cardiovascular events [6]. A population-based longitudinal study

Yasuharu Tabara

tabara@s-sph.ac.jp

1 Graduate School of Public Health, Shizuoka Graduate University of Public Health, Shizuoka, Japan

2 Center for Genomic Medicine, Kyoto University Graduate School of Medicine, Kyoto, Japan of older adults (mean age 92.1 years old) [7] clearly showed that the different associations between BP and cardiovascular and non-cardiovascular outcomes, i.e., higher systolic BP predicted death from cardiovascular disease, while lower systolic BP predicted death from non-cardiovascular causes, as the reason for the U-shaped association between $\mathrm{BP}$ and all-cause mortality.

These observational studies had one thing in commonin the oldest-old cohort ( $\sim>80$ years) BP in the normal range was associated with a less favorable prognosis and outcome. In nature, BP increases with age; however, it was reported to decrease for more than a decade before death in individuals dying at 60 years and older [8]. This unexpected fall in BP may partly be explained by potential comorbidities or poor functional status [9]. Therefore, the nonrandomized epidemiological associations of low BP with higher mortality in older individuals may partly be accounted for by reverse causation [10]. Because frailty, a clinical syndrome characterized by multiple features in older adults [11], but not the accumulation of potential comorbidities increases the BP drop before death [8], frailty may be a modifiable factor for the relationship between unexpected BP fall and mortality. Odden et al. [12] reported findings supporting this from the analysis using the National Health and Nutrition Examination Survey data set, a nationally representative survey of a noninstitutionalized US population. They reported that faster-walking $(0.8 \mathrm{~m} / \mathrm{s}$ or faster) older participants with elevated systolic BP $(\geq 140 \mathrm{mmHg})$ had a higher mortality rate. However, among the participants who did not complete the walk test, participants with elevated systolic BP had a lower mortality rate irrespective of antihypertensive medication status. We should consider frail status in the interpretation of BP values in oldest-old adults.

In this issue of Hypertension Research, Inoue et al. [13] reported that mortality rate in frail older patients with hypertension (mean age: 78 [71-84] years) did not differ between systolic $\mathrm{BP}<140 \mathrm{mmHg}[\mathrm{HR}=4.72,95 \% \mathrm{CI}$ : $1.67-16.90)]$ and $\mathrm{BP} \geq 140 \mathrm{mmHg}[\mathrm{HR}=3.56,95 \% \mathrm{CI}$ : 1.16-13.40] groups even in a sub-analysis of an older $(\geq 75$ years) population, though the mortality rates of both groups 


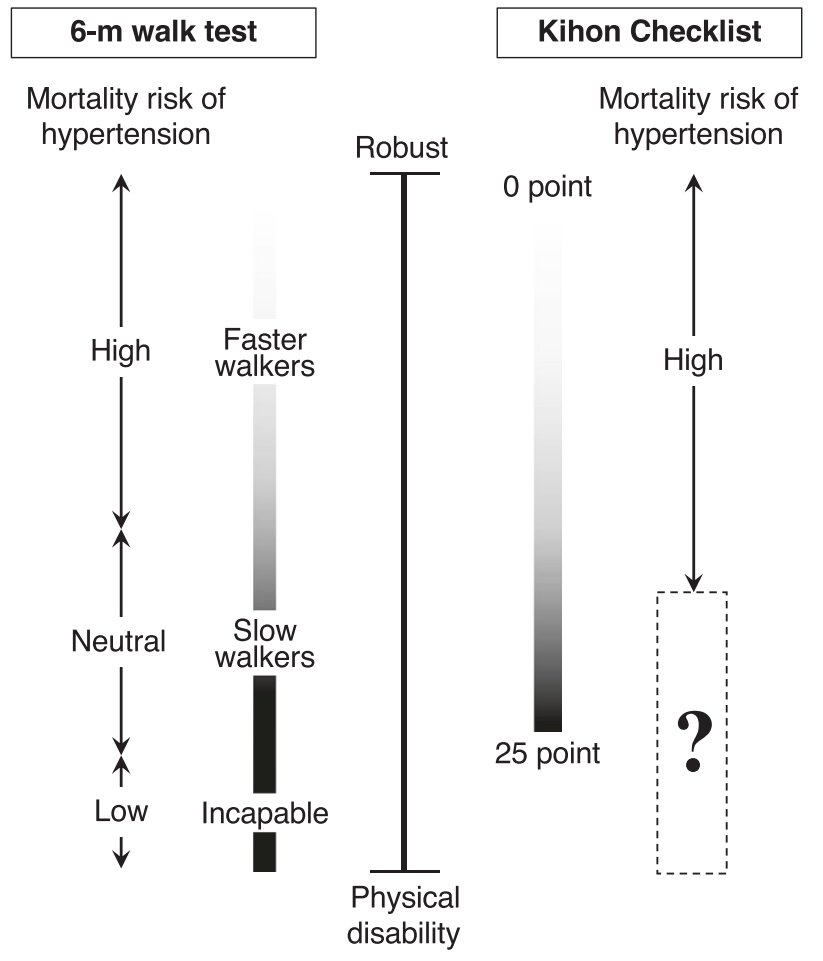

Fig. 1 Frailty status and its impact on mortality risk of hypertension.

were significantly higher when it was compared with that of non-frail patients with systolic $\mathrm{BP}<140 \mathrm{mmHg}$. An important dissimilarity between this study and Odden's study [12] was the definition of frailty; this study used the Kihon Checklist score, a comprehensive questionnaire for the physical, psychological, functional, and social statuses of nondisabled older adults, while Odden et al. used 6-m walk speed. Although the Kihon Checklist score closely correlates with the Cardiovascular Health Study frailty index [14], Odden's criteria might have identified more severe physical frailty cases (Fig. 1). Given the methodological differences, the results of these studies could not be simply compared; however, when we considered frail individuals in Inoue's study as mild cases, the modestly high hazard ratio in the systolic $\mathrm{BP}<140 \mathrm{mmHg}$ group might be of importance. Because the confidence interval of the hazard ratio was very wide, owing to the limited number of the study population, I hope that this study will have more participants and provide results of the extended analysis for us. Home BP measurement would also be variable in clarifying the clinical and epidemiological significance of low to normal BP in frail older adults [15]. The priority given to aggressive BP reduction in frail older adults requires further evaluation by randomized clinical trial settings.

Acknowledgements No financial support was received for this study.

\section{Compliance with ethical standards}

Conflict of interest The author declares no competing interests.

Publisher's note Springer Nature remains neutral with regard to jurisdictional claims in published maps and institutional affiliations.

\section{References}

1. Satish S, Freeman DH Jr, Ray L, Goodwin JS. The relationship between blood pressure and mortality in the oldest old. J Am Geriatr Soc. 2001;49:367-74.

2. Jacobs JM, Stessman J, Ein-Mor E, Bursztyn M. Hypertension and 5-year mortality among 85-year-olds: the Jerusalem longitudinal study. J Am Med Dir Assoc. 2012;13:759.e1-759.e6.

3. Rådholm K, Festin K, Falk M, Midlöv P, Mölstad S, Östgren CJ. Blood pressure and all-cause mortality: a prospective study of nursing home residents. Age Ageing. 2016;45:826-32.

4. Douros A, Tölle M, Ebert N, Gaedeke J, Huscher D, Kreutz R, et al. Control of blood pressure and risk of mortality in a cohort of older adults: the Berlin Initiative Study. Eur Heart J. 2019;40:2021-8.

5. Benetos A, Labat C, Rossignol P, Fay R, Rolland Y, Valbusa F, et al. Treatment with multiple blood pressure medications, achieved blood pressure, and mortality in older nursing home residents: the PARTAGE study. JAMA Intern Med. 2015;175:989-95.

6. Delgado J, Masoli JAH, Bowman K, Strain WD, Kuchel GA, Walters K, et al. As part of the Ageing Well Programme of the NIHR School for Public Health Research, England. Outcomes of treated hypertension at age 80 and older: cohort analysis of 79,376 individuals. J Am Geriatr Soc. 2017;65:995-1003.

7. Lv YB, Gao X, Yin ZX, Chen HS, Luo JS, Brasher MS, et al. Revisiting the association of blood pressure with mortality in oldest old people in China: community based, longitudinal prospective study. BMJ. 2018;361:k2158.

8. Delgado J, Bowman K, Ble A, Masoli J, Han Y, Henley W, et al. Blood pressure trajectories in the 20 years before death. JAMA Intern Med. 2018;178:93-99.

9. Satish S, Zhang DD, Goodwin JS. Clinical significance of falling blood pressure among older adults. J Clin Epidemiol. 2001;54:961-7.

10. Ravindrarajah R, Hazra NC, Hamada S, Charlton J, Jackson SHD, Dregan A, et al. Systolic blood pressure trajectory, frailty, and allcause mortality $>80$ years of age: cohort study using electronic health records. Circulation. 2017;135:2357-68.

11. Fried LP, Tangen CM, Walston J, Newman AB, Hirsch C, Gottdiener J, et al. Cardiovascular Health Study Collaborative Research Group. Frailty in older adults: evidence for a phenotype. J Gerontol A Biol Sci Med Sci. 2001;56:M146-M156.

12. Odden MC, Peralta CA, Haan MN, Covinsky KE. Rethinking the association of high blood pressure with mortality in elderly adults: the impact of frailty. Arch Intern Med. 2012;172:1162-8.

13. Inoue T, Matsuoka M, Shinjo T, Tamashiro M, Oba K, Kakazu M, et al. Blood pressure, frailty status, and all-cause mortality in elderly hypertensives; the Nambu cohort study. Hypertens Res. 2021. https://doi.org/10.1038/s41440-021-00769-0 In press.

14. Satake S, Senda K, Hong YJ, Miura H, Endo H, Sakurai T, et al. Validity of the Kihon Checklist for assessing frailty status. Geriatr Gerontol Int. 2016;16:709-15.

15. Murakami K, Asayama K, Satoh M, Hosaka M, Matsuda A, Inoue $\mathrm{R}$, et al. Home blood pressure predicts stroke incidence among older adults with impaired physical function: the Ohasama study. J Hypertens. 2017;35:2395-401. 